\title{
The effect of simvastatin on relapse of tooth movement and bone mineral density in rats measured by a new method using microtomography ${ }^{1}$
}

\author{
Giovanni Modesto Vieira', Sacha Braun Chaves ${ }^{\mathrm{II}}$, Vânia Maria Moraes Ferreira ${ }^{\mathrm{III}}$, Karina Maria Salvatore de Freitas ${ }^{\mathrm{IV}}$, \\ Rivadávio Fernandes Batista Amorimv
}

DOI: http://dx.doi.org/10.1590/S0102-865020150050000003

${ }^{\mathrm{I}}$ Fellow PhD degree, Postgraduate Program in Medical Sciences, Department of Pathology, Federal University of Brasilia (UnB), Brazil. Intellectual and scientific content of the study; technical procedures; acquisition, analysis and interpretation of data; manuscript writing.

IIPhD, Associate Professor, Institute of Biological Sciences, Department of Genetics and Morphology, UnB, Brasilia-DF, Brazil. Technical procedures; acquisition, analysis and interpretation of data.

IIIPhD, Associate Professor, Postgraduate Program in Medical Sciences and Behavioral Neuroscience, UnB, Brasilia-DF, Brazil. Technical procedures, acquisition of data.

${ }^{\mathrm{IV}} \mathrm{PhD}$, Professor, Postgraduate Program in Orthodontics, Uninga University, Bauru-SP, Brazil. Analysis and interpretation of data, critical revision. ${ }^{v} \mathrm{PhD}$, Associate Professor of Pathology, Coordinator, Postgraduate Program in Medical Sciences, UnB, Brasilia-DF, Brazil. Conception, design, intellectual and scientific content of the study; analysis and interpretation of data; critical revision.

\section{ABSTRACT}

PURPOSE: To evaluate the effect of simvastatin on relapse of tooth movement in rats using microtomography (micro CT), as well as the correlation of bone density with the orthodontic relapse.

METHODS: Twenty-five adult male Wistar rats, divided into two groups, had stainless steel springs installed on left maxillary first molar. The molars were moved for 18 days, and after removing the springs, were applied by oral gavage, $5 \mathrm{mg} / \mathrm{kg}$ of simvastatin in the experimental group for 20 days. Tooth relapse was assessed with a micro CT scanner, and the images chosen through the Data Viewer software 1.5.0.0 had their measurement guides made and checked by the software Image ProR plus 5.1, and compared by MannWhitney test. After rats were sacrificed, bone mineral density was evaluated by micro CT through the software CT Analyzer 1.13 and compared by independent T-test, as well as by Spearman correlation test.

RESULTS: Relapse and bone mineral density (BMD) was lower in the experimental group than in the control group, however without a statistically significant difference.

CONCLUSION: Simvastatin did not inhibit the relapse of tooth movement in rats, and there was no correlation between bone density and orthodontic relapse.

Key words: Recurrence. Simvastatin. X-Ray Microtomography. Densitometry. Rats. 


\section{Introduction}

All orthodontic movement requires a retention phase, which aims to stabilize the tooth elements in its new position, allowing the periodontal tissues to remodel and settle the space balance newly established ${ }^{1}$.

However, this balance not always occurs, and the exacerbated remodeling of the periodontium causes the relapse, i.e., the return of the original malocclusion, or dental crowding, because the occlusal instability after orthodontic treatment is common in almost all patients ${ }^{2}$.

The etiology of relapse is multifactorial, varying from muscle disorders and harmful oral habits, changes in dental arch form, unfavorable growth pattern, to the stretch of the transeptal fibers $^{3}$, and also has its origin due to the nature of immature and slightly mineralized bone tissue, which surrounds the tooth elements that were moved ${ }^{4}$.

Recently, it was found that most of the relapse occur within the first hours after the removal of orthodontic forces ${ }^{5}$ being crucial the process of alveolar bone remodeling in tooth movement relapse $^{6}$ and that fixed retainers are not always effective to prevent tooth relapse ${ }^{7}$.

Some authors proposed the control of relapse through pharmaceuticals, like the bisphosphonates ${ }^{8}$, (but its potential risks, such as osteonecrosis, not enable it for clinical use $\mathrm{e}^{9}$ ), osteoprotegerin $^{10}$, relaxin ${ }^{11}$ (hormones that can have another clinical effect).

The simvastatin is a drug related to the anabolic phase ${ }^{6}$, increasing the bone density ${ }^{12,13}$, and it was reported that simvastatin promotes osteoblasts activity and inhibits the osteoclastic activity ${ }^{14}$.

This work aimed to test the inhibition of the relapse of tooth movement by simvastatin in rats using a new micro CT methodology, with better accuracy than the current methods, as well as to correlate these findings with areas of tissue remodeling by bone densitometry analysis. It was hypothesized that the simvastatin inhibits the relapse of tooth movement in rats, through inhibition of bone resorption (and the increase in bone formation) with increase in bone mineral density, and that a correlation would be found between bone mineral density and relapse.

\section{Methods}

Research approved by Ethics Committee of Animal Use of the University of Brasilia (UnB-70872012).
The sample comprised 25 adult male Wistar rats (Rattus Norvegicus albinus), with four months of age (mean of 133 days), weighing on average $354 \pm 33$ grams. They were kept in standardized conditions with water and feed ad libitum, ambient temperature and light-dark cycle of 12 hours (06:00-18:00).

The animals were divided into two groups, 15 specimens in the experimental group and 10 specimens in the control group. The tooth elements to be studied were the maxillary first molars, with the left side representing the experimental side.

Group I: comprised 10 control animals that were sacrificed in the thirty-ninth day, with 18 days of induced tooth movement, with the application of $0.5 \%$ carboxymethyl cellulose $(\mathrm{m} / \mathrm{v})$ from the 19 th day until the 38 th day (20 days).

Group II: composed of 15 animals that were also sacrificed in the thirty-ninth day, with 18 days of tooth movement, with the application of a simvastatin solution with $0.5 \%$ carboxymethyl cellulose $(\mathrm{m} / \mathrm{v})$ from the 19 th day until the 38 th day (20 days).

\section{Installation of the springs}

After anesthesia with ketamine $(80 \mathrm{mg} / \mathrm{kg})$ and xylazine $(10 \mathrm{mg} / \mathrm{kg})$, spiral springs were installed according to the model proposed by Heller and $\mathrm{Nanda}^{15}$, consisting of closed steel springs of 0.006 " x 0.022 " with the aid of $0.14 \mathrm{~mm}$ steel ties and $9 \mathrm{~mm}$ of length (Morelli-Sorocaba-Brazil), that was passed between the interproximal space from the first and second molars, holding one end of the spring between the left maxillary first molar and the lateral incisor of the same side.

The other end of the spring was attached to the maxillary incisor, through a hole between the two incisors performed with a spherical drill, to pass the $0.25 \mathrm{~mm}$ ligature wire (MorelliSorocaba-Brazil). In the maxillary incisors, a mesial and distal groove were created, with an inverted conical drill (HM 1006 $1 / 2$ FG Meissenger-Germany), for the fitting of two ligature steel wire of $0.25 \mathrm{~mm}$, which were fixed with composite resin (Filtek ${ }^{\mathrm{TM}}$ Z250 XT - 3M St. Paul, MN, USA). An initial force of $75 \mathrm{cN}$ was measured by a dynamometer (Correx haag-streit Ag, Koeniz, Switzerland). After the initial activation, the appliance has not received any reactivation during the experimental period. The movement occurred in mesial direction on the right maxillary first molar and was the object of study, despising the movement toward the palatal direction of the maxillary incisor on the same side (Figure 1). 


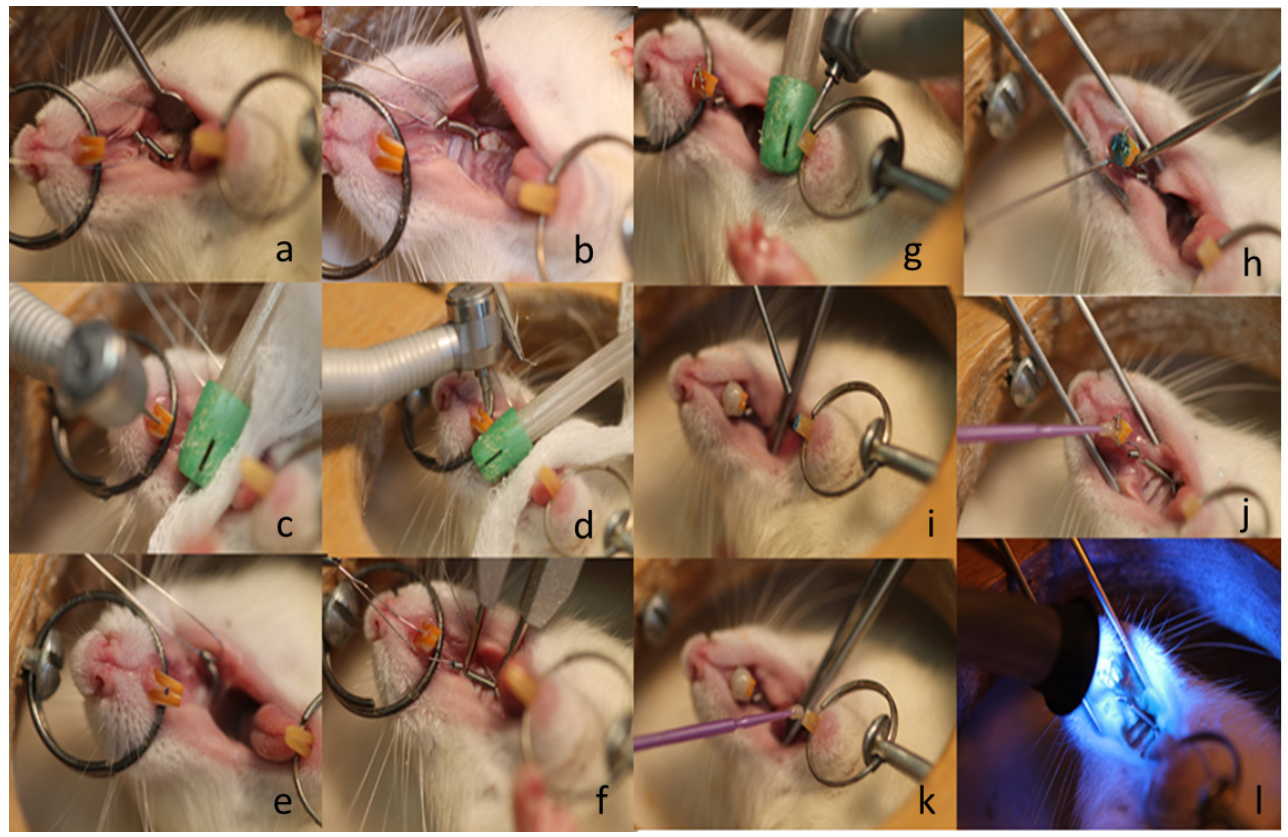

FIGURE 1 - Spring installation procedure. a. The installation of the wire ligature in the space between the first and second molar of the murines. b. Wire ligature attached to the end of the spring. c. The making of the center hole. d. Channel confection mesial and distal upper incisors. e. The view of the channels made. f. Spring measurement with compass of drypoint for measure $6 \mathrm{~mm}$ in length, corresponding to $75 \mathrm{cN}$ force. g. Antagonist teeth wear. h. Etching. i. Washing and drying. j. Primer application on the upper teeth. k. Primer application on the lower teeth. l. Application of composite resin and curing.

After installation of the springs, the animals were fed a ground ration to ease the effect of breakage of the devices. After 18 days of special diet, the animals had the springs removed, and had normal feeding, through conventional ration.

\section{Stock solution of simvastatin}

Simvastatin was administered by oral gavage at a $5 \mathrm{mg} /$ $\mathrm{kg}$ dose, being the volumes administered during 20 days, the day after the end of tooth movement. The $0.5 \%$ carboxymethyl cellulose was used as vehicle, being administered $400 \mu$ l of the drug or the placebo, via a probe for oral gavage coupled to a $1 \mathrm{ml}$ insulin syringe.

The stock solution of simvastatin was held according to Jabbari et al. ${ }^{16}$. It was dissolved $350 \mathrm{mg}$ of simvastatin, in $58.3 \mathrm{ml}$ of distilled water with the aid of a magnetic stirrer until complete homogenization and solubilization.

\section{Acquisition of images}

The acquisition of images was accomplished with the aid of a micro scanner Skyscan 1076 in vivo Bruker-micro CT, which generated micro CT radiographic images and subsequently were selected with the Data Viewer software version 1.5.0.0-Bruker-micro CT.
The following parameters were used for the generation of micro CT images, which took about seven minutes for each specimen: voltage $100 \mathrm{Kv}, 1 \mathrm{~mm}$ AI filter, resolution of $35 \mu \mathrm{m}$. It was taken 3 micro CT computed outlets: first micro CT, after the installation of the springs in the animals, which ranged from four to seven days, after the installation of the springs, second micro CT, after 18 days of tooth movement, third micro CT, after 20 days of prescription drugs.

\section{Selection and quantification of micro CT images}

The quantification of the tooth movement was performed through micro CT, with the software Data Viewer version 1.5.0.0-Bruker-micro CT who selected the 75 images for subsequent manufacture of guides and measurement of the tooth movement, through the software Image Pro $^{R}$ Plus 5.1-Media Cybernetics. The selection of 75 micro CT images was accomplished through the use of coordinates $\mathrm{x}, \mathrm{y}, \mathrm{z}$, representing their respective spatial plans: vertical, horizontal and transversal, which envisioned the roots (distal) of the first molar and (mesial) of the second molar of the murines, in the sagittal plane, what better approach of the following parameters: sharpness of images along the entire length of the roots, visualization of the three molars of murine in the same plane, and absence of artifact or overlap that precludes visualization of anatomical structures. 
The guides of measurement were performed with the software Image Pro ${ }^{\mathrm{R}}$ plus 5.1-Media Cybernetics, and consisted in a line representing the occlusal plane, which had as its origin and end: the mesiobuccal cusp tip of the left maxillary first molar and the distobuccal cusp tip of the left second molar. After tracing the occlusal plane, based on these dental elements, were drawn two perpendicular surfacing the most convex points of the distobuccal root of the left first molar and of the mesiobuccal root the left second molar, minimizing the measurement errors from the tipping and extrusion movements that occur on the first molar of the rat ${ }^{17}$ (Figure 2).

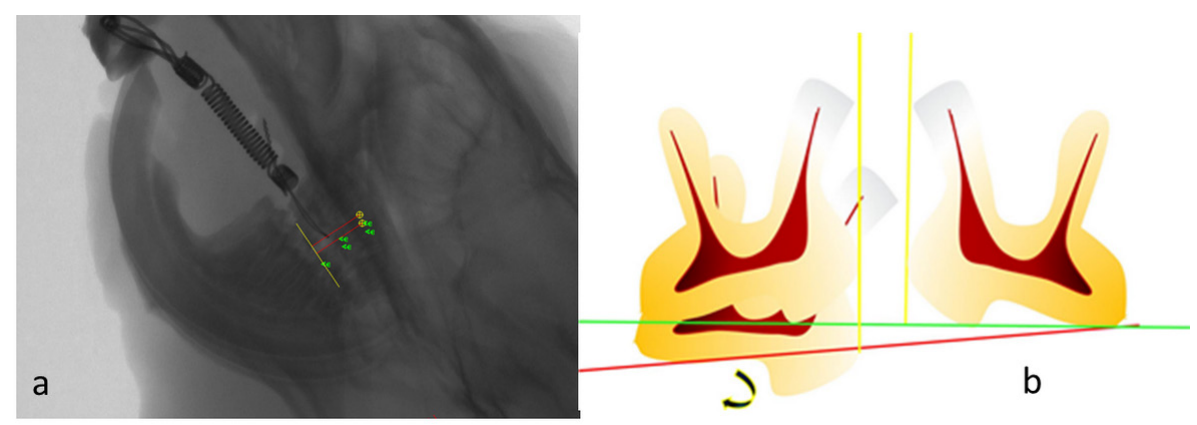

FIGURE 2 - a. The micro CT radiographic Image chosen with measurement guides. b. Schematic figure of the measuring guides.

Dental movement can be calibrated between these two Cybernetics (Figure 3). perpendiculars with the software Image Pro $^{R}$ plus 5.1-Media

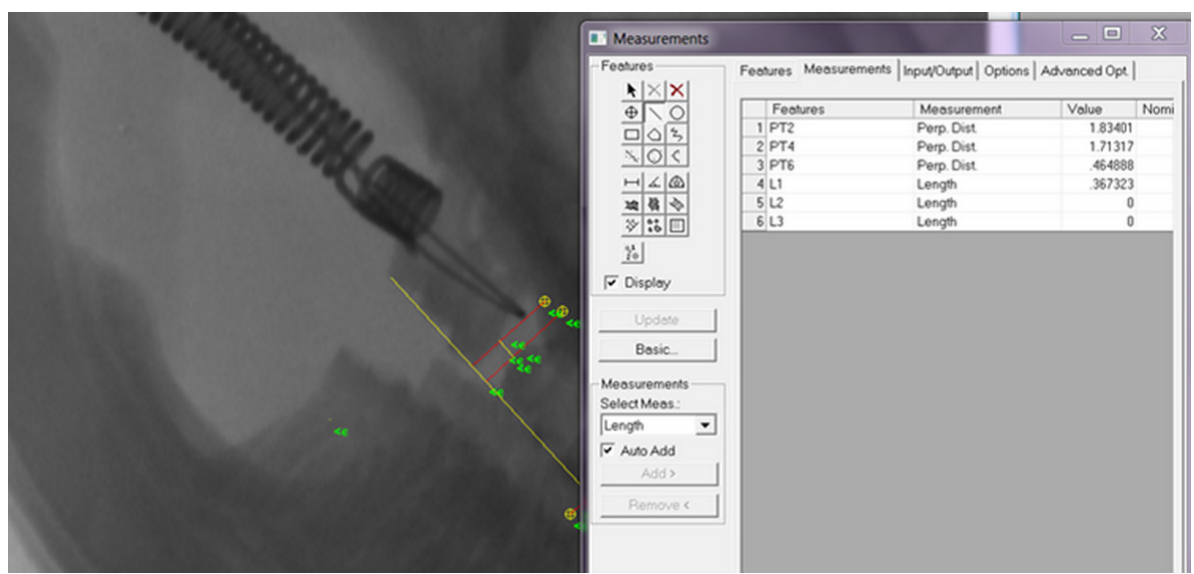

FIGURE 3 - Measurement of tooth movement through micro CT x-rays.

\section{Densitometr}

Bone mineral density (BMD) was performed with the CT Analyzer software 1.13 Bruker micro CT where regions of interest were established through the visualization of the mesial and distal root of the left maxillary first molars. To carry out this analysis, the $109 \mathrm{~mm}$ distance between the complete disappearances of the root of a microCT image to another image, was the parameter used for the delimitation of the upper and lower limit, the region comprised by micro CT images.

The use of a circle of $60 \times 60$ pixels, which would include the root and its surrounding bone structure, was used in the entire micro CT images analyzed (Figure 4). 


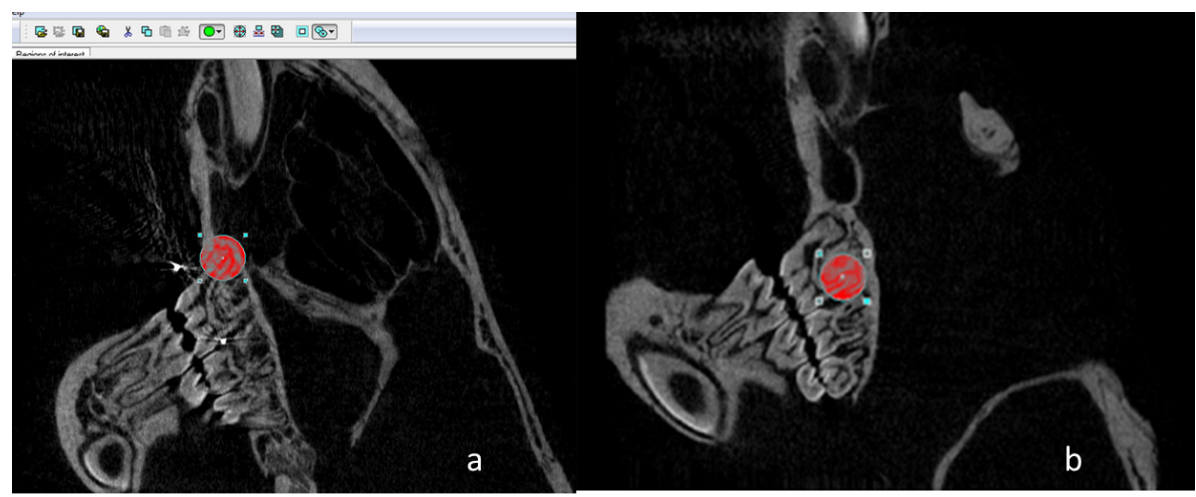

FIGURE 4 - Circle of 60 x 60 pixels including the mesial (a) and distal (b) region of the left maxillary first molar of a reconstructed micro CT image.

Euthanasia of animals was performed through a gas chamber in the vivarium of the institute of biological sciences at the University of Brasilia-UnB, through carbon monoxide gas for a period of 10 minutes, until the complete death of the animals.

\section{Statistical analysis}

A two-tailed hypothesis test was conducted with a significance level of 5\%, with the software Statistical Package for Social Sciences-SPSS-20.

Through a univariate analysis was conducted the Shapiro Wilk normality test, indicating that data did not follow the normal curve, requiring the use of nonparametric tests. The nonparametric Mann-Whitney test was used for evaluation of dental movement and relapse between the two groups. The weight of the animals and the bone densitometry comparison between the groups was assessed by independent T-test, because they followed the normal curve.

For the evaluation of intra-examiner error, were retraced and remeasured 75 guides with their respective measurements, 30 and 60 days after the completion of the initial measurements.

\section{Results}

\section{Analysis of tooth movement}

It was observed that the tooth elements of the murine gradually moved to a certain limit, after which (after the removal of springs) tended to return to its original position (relapse).

In the statistical analysis there was no statistical significance in the comparison between the two groups after the initial tooth movement (initial micro CT) and also no significant difference at the end of the 18th-day of movement (18d micro CT), as well as in the weight of the animals (Table 1).

TABLE 1 - Characteristics between the groups.

\begin{tabular}{|c|c|c|c|}
\hline & Characteristi & the groups & \\
\hline & Control $(\mathrm{n}=10)$ & Simvastatin $(\mathrm{n}=15)$ & \\
\hline Demographics & & & $\mathrm{p}$ value \\
\hline Gender M/F (\%) & $10 / 0(100)$ & $15 / 0(100)$ & \\
\hline Weight $_{\text {(a) }}$ & $350(320-381)$ & $371(356-385)$ & $0.195 *$ \\
\hline Initial Assessment & & & \\
\hline Initial Density (mesial rot) $_{(b)}$ & $0.241(0.149-0.276)$ & $0.221(0.107-0.264)$ & $0.395^{*}$ \\
\hline Initial Density (distal root) $_{(\mathrm{c})}$ & $0.246(0.197-0.273)$ & $0.267(0.248-0.311)$ & $0.399^{*}$ \\
\hline Initial MicroCT $_{(\mathrm{d})}$ & $0.125(0.109-0.154)$ & $0.154(0.142-0.186)$ & $1.000 \dagger$ \\
\hline a grams & $\begin{array}{l}\text { b,c Denisty bone mineral: avarage } \\
\text { (Confidence intercal } 95 \%)\end{array}$ & $\begin{array}{l}d \text { image micro CT median } \\
\text { (percentis 25-75) }\end{array}$ & $\begin{array}{l}\text { *Independent samples } t \\
\dagger \text { Mann Whitney test }\end{array}$ \\
\hline
\end{tabular}

No statistically significant difference was found between the two groups examined, regarding the final micro CT (Table 2). 
Vieira GM et al.

TABLE 2 - Final bone mineral density and relapse evaluated by Micro-CT of the mesial and distal root of the left maxillary first molar.

\begin{tabular}{|c|c|c|c|c|c|}
\hline & & & & & \\
\hline & & $1(n=10)$ & & astatin & \\
\hline & 0.455 & 0.022 & -0.028 & 0.027 & -0.012 \\
\hline Distal root & $\mathrm{p}$-value & standart deviation & average & standart deviation & average \\
\hline Mann Whitr & & & & & \\
\hline & P-value & median & $\begin{array}{l}\text { standart } \\
\text { deviation }\end{array}$ & median & $\begin{array}{l}\text { standart } \\
\text { deviation }\end{array}$ \\
\hline & 1.000 & 0.0040 & 0.0025 & 0.0041 & 0.1145 \\
\hline
\end{tabular}

Analysis of bone densitometry

\section{Mesial root}

Bone mineral density has tended to reduce as the tooth movement occurred, stabilizing in the control group with values in $\mathrm{g} / \mathrm{cm}^{3}$ lesser than the initial ones, after removal of the springs, during the period of relapse in the simvastatin group (Figures 5 and 6 ), but no statistically significant difference was found between the two groups regarding bone density (Table 2).

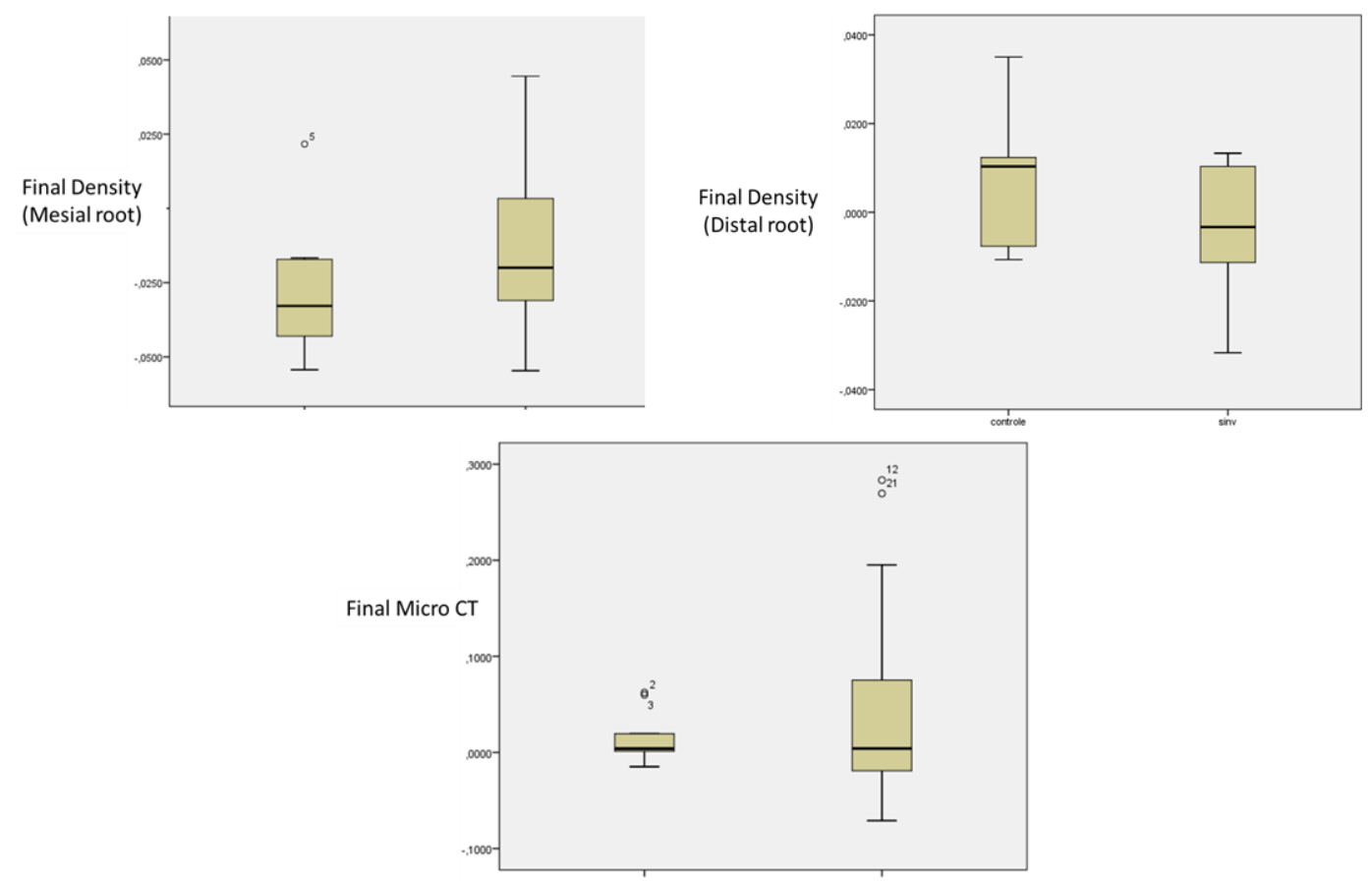

FIGURE 5 - Box plot Chart: final micro CT and final densitometry. 


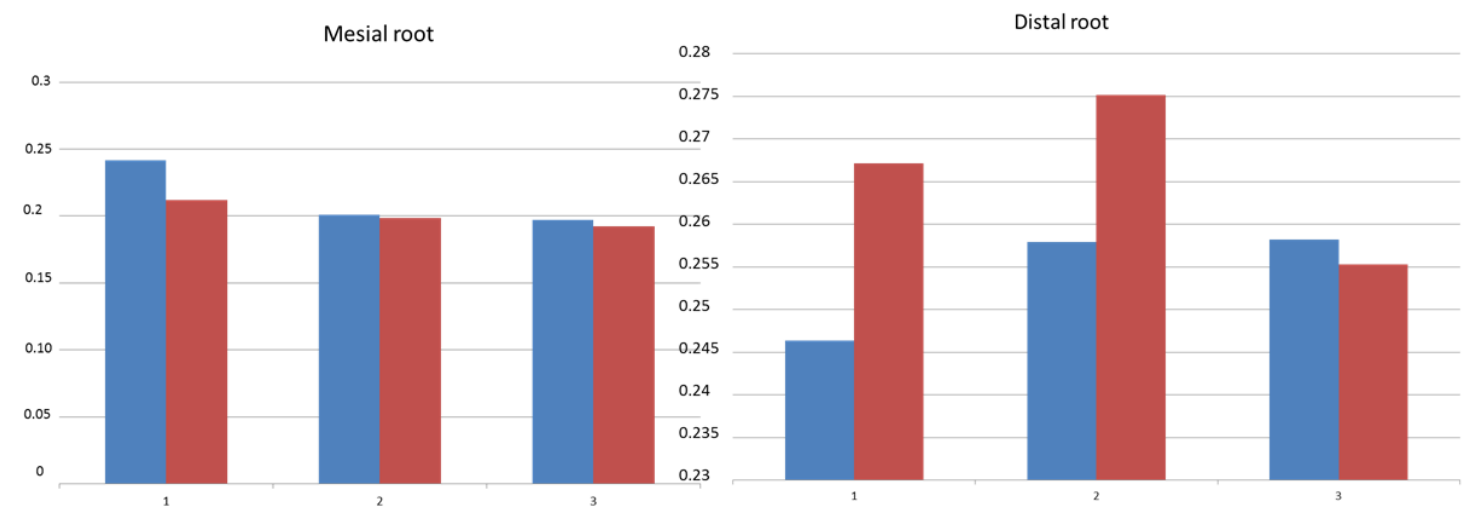

FIGURE 6 - Bone Mineral Density $\left(\mathrm{g} / \mathrm{cm}^{3}\right)$ of control (blue) and simvastatin (red) during: beginning of movement 4 to 7 days (1), movement at 18 days (2) and beginning of application of simvastatin, and end of the movement (3) with 38 days.

\section{Distal root}

Bone mineral density has tended to increase as the tooth movement occurred, stabilizing in the control group with values in $\mathrm{g} / \mathrm{cm}^{3}$ greater than the initial ones, after removal of the springs, during the period of relapse in the simvastatin group (Figures 5 and 6 ), but no statistically significant difference was found between the two groups regarding bone density (Table 2).

\section{Bivariate correlation}

No significant correlation was found between relapse represented by the difference in final micro $\mathrm{CT}$ and bone mineral density of the mesial and distal root of the left maxillary first molar (Table 3).

TABLE 3 - Correlation between final bone density and relapse (Micro-CT).

\begin{tabular}{ccc}
\hline & & Groups \\
\cline { 2 - 3 } Spearman Correlation & Final Density bone & Fina Micro CT \\
\hline Distalroot P-Value & 0.404 & 0.404 \\
\hline Spearman correlation & Final Density bone & Final Micro CT \\
Mesialroot P-Value & 0.281 & 0.281 \\
\hline
\end{tabular}

\section{Discussion}

The drug simvastatin is a drug related to the treatment of hypercholesterolemia and hyperlipidemia ${ }^{18}$, acting as a competitive inhibitor of 3-hydroxy-3-methylglutaryl-coenzyme A reductase (HMG-Co-a), limiting the enzyme rate responsible for the cholesterol synthesis.

In the last decade, emphasis was given on the effect of the drug on bone tissue being observed: expression of bone morphogenetic protein (BMP-2), when their local administration in bone tissue ${ }^{19}$, in vitro bone inductive effect ${ }^{20}$, stimulating mineralization and differentiation of mesenchymal cells into new cells responsible for bone neoformation ${ }^{21}$.

The application of simvastatin was performed avoiding high doses are out of normal prescription ${ }^{22}$, and $10 \mathrm{mg} / \mathrm{kg}$ a day in rats is a high dose that would correspond in pharmacokinetic terms, to $70 \mathrm{mg} / \mathrm{kg}$ a day in humans, and these high doses of simvastatin increase the risk of liver failure, kidney diseases, rhabdomyolysis and myalgia ${ }^{23}$. So it was adopted the oral dose of $5 \mathrm{mg} / \mathrm{kg}$ a day in rats, equivalent to 20 to $40 \mathrm{mg}$ daily dose normally used in humans.

In the present study, simvastatin did not interfere on relapse of tooth movement, with no statistically significant values, contrary to others works ${ }^{6,24}$, what may be due to greater effectiveness of the intravenous administration used for their researches. However, the risk of crusts or scabs in surrounding skin, due to local daily drug injections ${ }^{25}$, in a long period, facilitated the adoption of the mouth as the most suitable for a study during this time of observation.

Actually, there are works that attest that the simvastatin is not well absorbed, and less than $5 \%$ of the drug is in the 
bloodstream, after application by oral via ${ }^{14}$. However, it is wellargued that osteoblasts and osteoclasts may be well exposed to low concentrations orally ${ }^{14}$.

In addition, the assessment method used by other researches ${ }^{6,24}$, is more prone to failure, considering that the various stages of the transfer process, than a direct analysis on tomographic images in real scale. And photo editing programs do not have sufficient accuracy, because they are not especially manufactured for accurate measurements in appropriate scale, compared to the sophistication of image processing software, whose analysis tool provides advanced measurement of microscopic and radiographic images, without the need of using the macro. On the other hand, a digital caliper that using directly in the mouth of animals, between the incisors and the first molars ${ }^{24}$, limits the accuracy and precision of the measurements, including the extrusion and tipping of the molars due to the induced tooth movement ${ }^{17}$, besides the continuous incisors eruption, typical to the rodent animals ${ }^{26}$.

Despite the stimulus to mineralization and differentiation, responsible for bone neoformation ${ }^{17}$, there is no evidence of increased bone density around the mesial and distal root, proving bone neoformation ${ }^{17}$, after the removal of the orthodontic device and use of simvastatin by oral gavage, instead, there was a decrease in bone mineral density after the induced tooth movement and drug institution.

Simvastatin inhibits the subproducts of the mevalonate, specifically the isoprenoids farnesyl diphosphate and geranilgeranil diphosphate that have ligating affinity for the terminal carbons of the small ligating proteins called GTP, forming the so-called prenylated cytosolic proteins.

An example of these prenylated proteins are the Rac and Rho, which are essential in the activation of cell polarization and motility, including macrophages and osteoclasts ${ }^{27}$.

The bisphosphonates also inhibit prenylation, inhibiting osteoclastic function and bone resorption, and ponder that the simvastatin would have similar effect ${ }^{28}$, but so would an increase in BMD after application of the drug, taking into account the effect of the drug on catabolic strand of the bone tissue.

However, another research found that at low doses $(1,0 \mathrm{mg} / \mathrm{kg}$ to $5,0 \mathrm{mg} / \mathrm{kg})$, simvastatin exhibits effect of reduction of BMD in rats, with decrease in bone formation and increase in bone reabsorption ${ }^{27}$.

Actually, the results of the present study confirm the findings of Maritz et al. ${ }^{27}$ and Park ${ }^{14}$, that found decrease in bone deposition and increase in bone resorption with decrease of BMD, with the use of low doses of $\operatorname{simvastatin}^{14,27}(1.0 \mathrm{mg} / \mathrm{kg}$ to $5 \mathrm{mg} / \mathrm{kg})$.

According to these authors, only with high doses of simvastatin $(20 \mathrm{mg} / \mathrm{kg})$ there will be an increase in bone formation, with any change in the rate of bone mineral density ${ }^{14,27}$. Osteoblasts would be preferentially stimulated, with the maintenance or increase in bone mineral density ${ }^{27}$.

And this discrepancy in the response of bone remodeling to the doses of simvastatin, could be explained by the difference in sensitivity between the cells responsible for the formation and destruction of the bone tissue, with greater sensitivity by osteoclasts to the simvastatin ${ }^{27}$, which would present a different effect of prenylation, found by the study of the drug in vitro ${ }^{28}$.

This also occurs with bisphosphonates, which also inhibit the prenylation, but whose effects on osteoclastic cells are dependent on the drug dosage. The EB-1053 inhibits the osteoclastic function in normal doses, but in low dosage increases osteoclastic function $^{29}$. This could explain the decrease in bone mineral density to simvastatin in the specimens studied.

Interesting, that as the reduction in bone mineral density was not significant between the groups, the rate of resorption also did not present accelerated, with increase in catabolic turnover, to the point of increase relapse of induced tooth movement in the simvastatin group, statistically proven by analysis of micro$\mathrm{CT}$, and by the lack of correlation between the relapse and bone density.

Theoretically, there will only be inhibition of relapse of induced tooth movement, with a decrease in the rate of bone mineral resorption, resulting from inhibition of osteoclasts and osteoblasts stimulation, resulting in an increase of BMD and bone formation, which in fact did not occur in the present research.

\section{Conclusions}

Simvastatin did not inhibit relapse of induced tooth movement, and there has been a decrease in BMD in the mesial and distal root of the left maxillary first molars, after the drug administration, which was not statistically significant between the two groups.

There was no correlation between the bone density of the mesial and distal root of the left maxillary first molar that was moved and its relapse.

\section{References}

1. Littlewood SJ, Millett DT, Doubleday B, Bearn DR, Worthington HV. Orthodontic retention: a systematic review. J Orthod. 2006;33(3):205-12. doi: 10.1179/14653120722770.

2. Riedel RA, Brandt S. Dr. Richard A. Riedel on retention and relapse. J Clin Orthod. 1976;10(6):454-72. PMID: 1074893.

3. Littlewood SJ, Russell JS, Spencer RJ. Why do orhtodontic cases relapse? Orthod Update. 2009;2:43-9. 
4. Hsu JT, Chang HW, Huang HJ, Yu JH, Yu F, Tu MG. Bone density change around teeth during orthodontic treatment. Clin Oral Invest. 2011;15(4):511-9. doi: 10.1007/s00784-010-0410-1.

5. Franzen JT, Brudvik P, Radunovic VV. Periodontal tissue reaction during orthodontic relapse in rat molars. Eur J Orthod. 2011;35(2):152-9. doi: 10.1093/ejo/cjr127.

6. Han G, Chen Y, Hou J, Liu C, Chen C, Zhuang J, Meng W. Effects of simvastatin on relapse and remodeling of periodontal tissues after tooth movement in rats. Am J of Orthod Dentofacial Orthop. 2010;138(5):550-7. PMID: 21055594.

7. Littlewood SJ, Millett DT, Doubleday B, Bearn DR, Worthington HV. Retention procedures for stabilizing tooth position after treatment with orthodontic braces. Cochrane Database Syst Rev. 2004;(1):CD002283. doi: 10.1002/14651858.

8. Adachi H, Igarashi K, Mitani H, Shinoda H. Effects of topical administration of a bisphosphonate (risedronate) on orthodontic tooth movements in rats. J Dent Res. 1994;73(8):1478-86. doi: 10.1177/00220345940730081301.

9. Zahroswski JJ. Bisphosphonate treatment: an orthodontic concern calling for a proactive approach. Am J Orthod Dentofacial Orthop. 2007;131(3):311-20. doi: 10.1016/j.ajodo.2006.09.035.

10. Hudson JB, Hatch N, Hayami T, Shin JM, Stolina M, Kostenuik PJ, Kapila S. Local delivery of recombinant osteoprotegerin enhances postorthodontic tooth stability. Calcif Tissue Int. 2012;90(4):33042. doi: 10.1007/s00223-012-9579-4.

11. Hirate Y, Yamaguchi M, Kasai K. Effects of relaxin on relapse and periodontal tissue remodeling after experimental tooth movement in rats. Connect Tissue Res. 2012;53(3):207-19. doi: 10.3109/03008207.2011.628060.

12. Singh KS, Dodward V, Dhariwal G. Simvastatin and periodontal regeneration. J Pharm Biomed Sci. 2012;21(25):1-4.

13. Uzzan B, Cohen R, Nicolas P, Cucherat M, Perret GY. Effects of statins on bone mineral density: A meta-analysis of clinical studies. Bone. 2007;40(6):1581-7. PMID: 17409043.

14. Park BJ. The use of simvastatin in bone regeneration. Med Oral Patol Oral Cir Bucal. 2009;14(9):485-8. PMID: 19415061.

15. Heller IJ, Nanda R. Effect of alteration of periodontal fibers on orthodontic tooth movement. An experimental study. Am J Orthod. 1979;75(3):239-58. PMID: 285607.

16. Jabbari M, Zohreh Rostami J, JenabI A, Zahedi-Shoolami L, Mooraki A. Simvastatin ameliorates gentamicin-induced renal injury in rats. Saudi J Kidney Dis Transpl. 2011;22(6):1181-6. doi: 10.3109/0886022X.2011.560987.

17. Gonzalesa C, Hotokezakab H, Araic Y, Ninomiyad T, Tominagaa J, Janga I, Hotokezaka Y, Tanaka M, Yoshida N. An In vivo 3D Micro$\mathrm{CT}$ evaluation of tooth movement after the application of different force magnitudes in rat molar. Angle Orthod. 2009;79(4):703-14. doi: 10.2319/071308-366.1.

18. Hassan MH, Elgayar MA, Ibrahim MT, Al-Gayyar HM. Antiinflammatory Effect of simvastatin-aspirin combination. Int J Pharm Sci Drug Res. 2011;3(2):89-96.

19. Mundy G, Garret R, Harris S, Chan J, Chen D, Rossini G, Boyce B, Zhao M, Gutierrez G. Stimulation of bone formation in vitro and in rodents by statins. Science. 1999;289(5446):1946-9. PMID: 10583956

20. Maeda T, Matsunuma A, Kurahashi I, Yanagawa T, Yoshida H, Horiuchi N. Induction of osteoclasts differentiation indices by statin in MC3T3-E1 cells. J Cell Biochem. 2004;92(3):458-71. PMID: 15156558
21. Houshmand B, Hassanizade R, Eslami B, Amouuei S, Dashti G, Morad G, Khojasteh A. Simvastatin and lovastatin induce ectopic bone formation in rat subcutaneous tissue. J Periodont Implant Dent. 2010;2(1):12-6. doi: 10.5681/jpid.2010.002.

22. Singh KS, Dodward V, Dhariwal G. Simvastatin and periodontal regeneration. J Pharm Biomed Sci. 2012;21(25):1-4.

23. Jadhav SB, Jain GK. Statins and osteoporosis: new role for old drugs. J Pharm Pharmacol. 2006;58(1):3-18. doi: 10.1211/jpp.58.1.0002.

24. Esfahani NEA, Sadeghian S, Razavi SM, Minaiyan M, Afsari E. The effects of simvastatin on bone remodeling, tooth movement and root resorption in orthodontic treatments. Biomed Pharmacol J. 2013;6(2):271-8. doi: 10.13005/bpj/414.

25. Thylin MR, McConnell JC, Schmid MJ, Reckling RR, Ojha J, Bhattacharyya I, Marx DB, Reinhardt RA. Effects of simvastatin gels on murine calvarial bone. J Periodontol. 2002;73(10):1141-8. PMID: 12416771.

26. Burn-Murdock RA. The length an eruption rates of incisors teeth in rats after one or more them had been unimpeded. Eur J Orthod. 1999;21(1):49-56. doi: 10.1093/ejo/21.1.49 49-56.

27. Maritz FJ, Conradie MM, Hulley PA, Gopal R, Hough S. Effect of statins on bone mineral density and bone histomorphometry in rodents. Arterioscler Thromb Vasc Biol. 2001;21(10):1636-41. PMID: 11597938.

28. Sugiyama M, Kodama T, Konishi K, Abe K, Asami S, Oikawa $\mathrm{S}$. Compactin and simvastatin, but not pravastatin, induce bone morphogenetic protein-2 in human osteosarcoma cells. Biochem Biophys Res Commun. 2000;271(3):688-92. PMID: 10814523.

29. van der Pluijm G, Binderup L, Bramm E, van der Wee-Pals L, De Groot H, Binderup E, Löwik C, Papapoulos S. Disodium 1-hydroxy3-(1-pyrrolidinyl)-propylidene-1,1-bisphosphonate (EB-1053) is a potent inhibitor of bone resorption in vitro and in vivo. J Bone Miner Res. 1992;7(8):981-6. PMID: 1442212.

\section{Correspondence:}

Rivadávio Fernandes Batista Amorim

Departamento de Patologia

Universidade Federal de Brasília

Campus Darcy Ribeiro-Faculdade de Medicina, Asa Norte

70910-900 Brasília - DF Brasil

Tel.: (55 61)3307-2560

Fax: (55 61)3107-1907

rivadavioamorim@hotmail.com

Received: Jan 16, 2015

Review: Mar 19, 2015

Accepted: Apr 18, 2015

Conflict of interest: none

Financial source: none

${ }^{1}$ Research performed at Laboratory of Genetic and Morphology, Department of Pathology, School of Medicine, University of Brasilia (UnB), Brazil. Part PhD degree thesis, Postgraduate Program in Medical Sciences, UnB. Tutor: Rivadávio Fernandes Batista Amorim. 